\title{
What is the Meaning of Clovis?
}

\section{by Robson Bonnichsen}

A major issue in archaeology and Quaternary geology alike concerns the peopling of the Americas. Central to this problem is Clovis, a pattern of artifacts from around 11,600 to 10,800 years ago. This article reviews the two major explanations proposed for Clovis, the migration and the environmental response models. The former proposes that big-game hunters crossed into North America from Northern Asia just before the end of the last glaciation, while the latter assumes that people already living in North America responded to natural environmental changes (deglaciation) by developing new hunting patterns. (Ed.)

\section{What is Clovis?}

A fundamental and unresolved problem in New World prehistory involves the peopling of the Americas. It entails answering the related questions of when, where, how, why, and by whom were the Americas peopled. A single facet of this problem concerns the origins of Clovis - an archaeological pattern dating between about 11,600 to 10,800 years ago. Characteristic of this pattern are diagnostic fluted projectile points that have a semi-triangular outline and long basal thinning flakes (flutes) removed from both faces to facilitate binding the spearshaft to the fluted point (Fig. 1). Other artifacts associated with Clovis include bifacially flaked knives, scraper knives, triangular end scrapers, and bone foreshafts and/or bone points. The people who used these tools were foragers and hunters who pursued large, now-extinet animals including a very large bison that has no modern equivalent, the mastodon and, particularly, the mammoth.

Migration vs Environmental Response

Two competing explanations, the migration and the environmental response models, have been proposed for the sudden intercontinental distribution of the Clovis pattern.

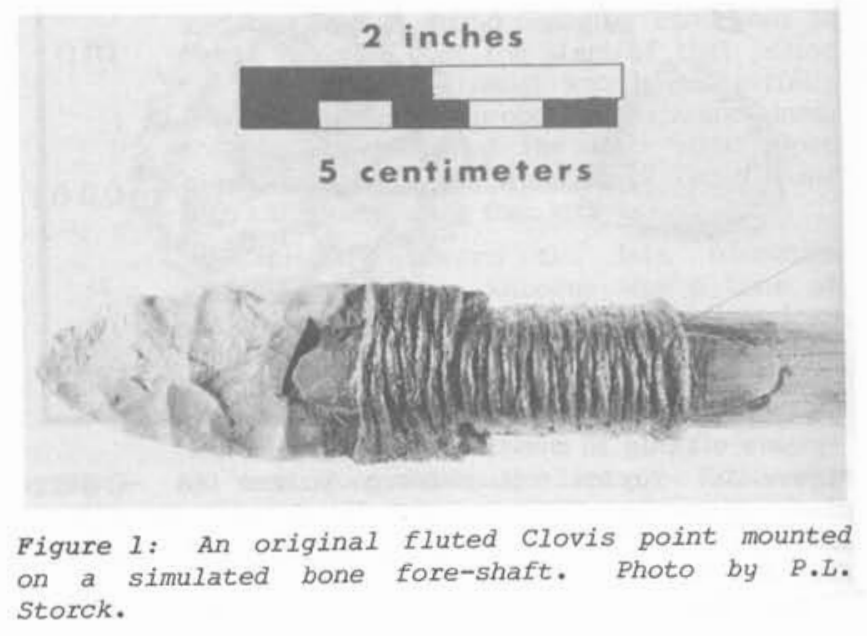


The more elegantly articulated and frequently cited of the two, the migration hypothesis, has been detailed in a series of papers spanning almost two decades by Haynes and Martin (Haynes, 1966; 1969; 1973, 1980; Martin, 1967, 1973, in Martin and Klein, 1984; Mosiman and Martin, 1975). These workers argue that about 12,000 years ago specialized big-game hunters adapted to Arctic conditions and crossed the Beringian Platform (the land mass connecting Asia and North America), just before it was drowned by rising sea levels at the end of the last Ice Age.

In one simulation model Mosiman and Martin proposed that as few as 100 human colonists could have initially occupied America by travelling down the ice-free corridor separating the Cordilleran and Laurentide ice sheets. At approximately the location of Edmonton, Alberta, a growing population (e.g. 2.3 individuals per generation) spread out in a southward-moving wave (Fig. 2). In their wake, the colonists left a landscape littered with the remains of large game animals. In approximately 1,000 years these big-game hunters eliminated approximately $70 \%$ of the terrestrial fauna in North and South America.

By contrast, the environmental-response model postulates quite another sequence of events. Of considerable importance here is the Milankovitch hypothesis, which proposes that the Earth is pulled out of preeise equilibrium by the gravitational force of other planets, affecting the precession of the equinoxes, orbital eccentricity, and obliquity of the rotational axis (Kutzbach, 1983, 1984). It is currently seen as the single most potent force causing changes in related environmental systems. Cyclical orbital variation can thus be seen to serve as a catalyst, forcing changes in linked atmospheric, climatic, geologic, glacial, biotic, and human adaptive systems. These cyclic changes are important for understanding the origin and extinction of biological organisms and human adaptive systems as well as the dispersion of plants, animals, and humans.

An orbital event coinciding with the end of the Pleistocene has special significance. The precession cycle governs change in the seasonal timing of perihelion (angle closest to the sun). The perihelion now occurs in January, but 11,000 years ago it would have oceurred in July, accounting for seasonal differences in solar radiation of about $7 \%$. It is a significant factor leading to the collapse of ice sheets, changes in positions of storm tracks, rising sea levels, increasing rates of vegetation change, the extinction of about $70 \%$ of terrestrial mammals, and the sudden emergence of new human adaptive systems in North and South America. Some details of the internal dynamics and linkages between systems are reported in a new study now in press (Ruddiman and Wright).

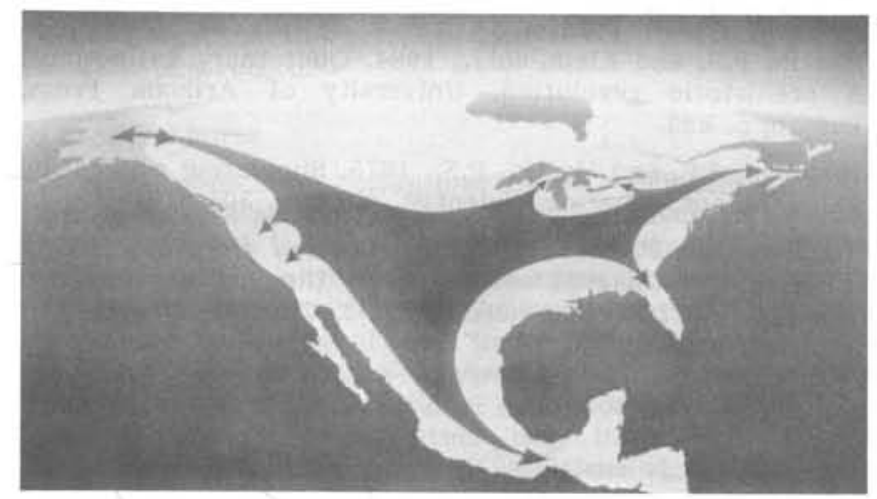

Figure 2: One generalized view of the distribution of the Early Paleo-Indians of North America, producers of the Clovis pattern. Artwork by $C$. Farley, Photo courtesy of Royal Ontario Museum.
Rather than viewing Clovis hunters as the primary eause of extinction of most large terrestrial mammals, the environmental-response model envisions vegetation as the critical link between climatic change and animals. Several workers have argued that during the last glacial interval, and perhaps earlier, plant communities formed mosaic patterns (Guthrie, and Graham and Lundelius, in Martin and Klein, 1984). The diversity of vegetation available allowed many taxa of megafauna to co-exist, but by the Late Pleistocene, these mosaic communities were replaced by more homogenous ones. The individualistic response of each taxon, according to its own parameters, led to a general reshuffling of plant and animal associations and the creation of new homogenous communities. Many of the large mammals were unable to adapt to the new vegetation associations. As animals experimented with eating new plants with antiherbivore defenses of toxic chemicals, they may have poisoned themselves.

The appearance of the Clovis archaeological pattern is coincident with other threshold events of the Earth's environmental systems during the Late Pleistocene (Bonnichsen et al., in Ruddiman and Wright, in press). Yet these correlations do not answer the question: Where did the Clovis pattern originate? Rather than explaining Late Pleistocene extinction and the sudden appearance of Clovis with the migration hypothesis, the environmental-response model assumes that human populations were already in America prior to the end of the last Ice Age. It proposes that global environmental change led to a disequilibrium between subsistence practices and the natural environment.

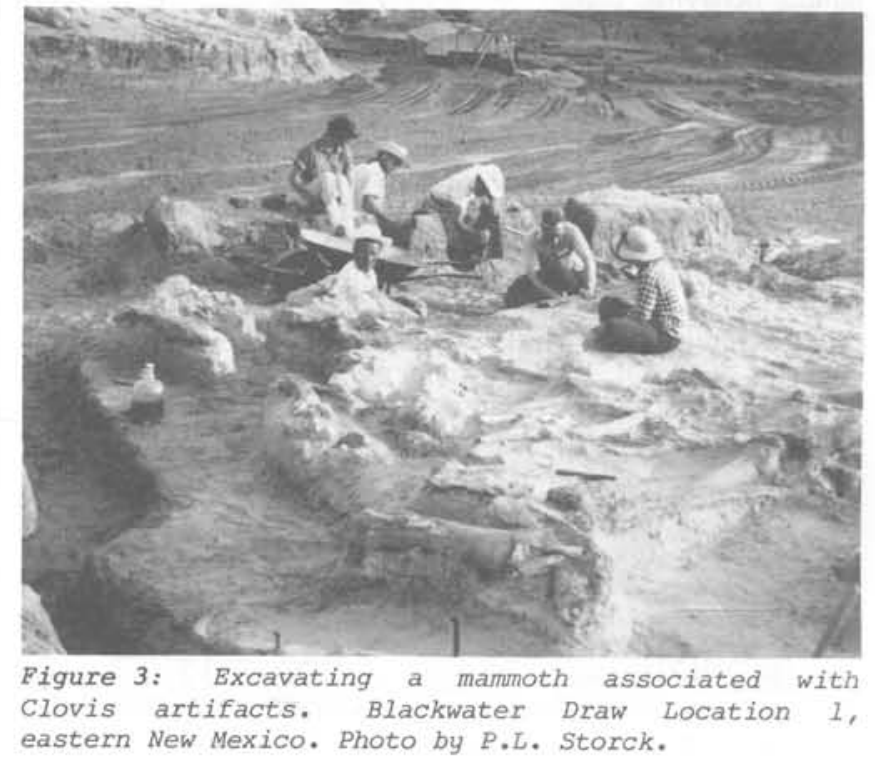

The relationship that humans had traditionally held with their environment was disrupted by the reorganization of plant and animal communities, which in turn affected human demographic patterns. Humans enhanced their survival success by responding to these rapidly changing circumstances and by changing their big-game hunting capabilities. Innovation acceptance of new traits, and restructuring their social and economic organizations to accommodate local contexts are the primary means by which humans responded to the Late Pleistocene threshold event.

\section{The Source of the Clovis Pattern}

Elements included in the Clovis pattern were likely derived from communal hunting patterns in northeast Asia. By Late Pleistocene time, human populations in eastern Siberia, northeastern and central China, and the Ukraine were armed with the knowledge for making lanceolate projectile points, 
bifacially flaked stone knives, triangular and serapers, and with techniques for flaking large mammal bones, constructing bone points and foreshafts, mining raw materials, and the skills needed for communal hunting.

With elimate warming at the end of Pleistocene time, the smaller Eurasian ice sheet, underwent ablation earlier than the American continental ice sheet. These circumstances may have set the stage for the movement of people in search of new environments. At the same time, glacial ice persisted longer in North America than Asia and may have produced an environmental lag effect in northern North America.

A small population of migrants from northeastern Asia may have arrived in North America during Late Pleistocene times with sophisticated ways to hunt large game animals. They met indigenous populations who had traditionally produced relatively simple wood, bone, and flaked stone artifacts - items with a low visibility in the archaeological record (Fig. 3).

\section{Spreading the Techno-Complex}

Under eonditions of environmental stress and declining animal populations, the innovation and diffusion of new ideas would have been readily accepted to offset deteriorating subsistence opportunities. Through a process of stimulus diffusion, this new "techno-complex" rapidly spread from group to group, each interpreting it in terms of their own traditions for making tools and ways of organizing human behavior, and in terms of the local context in which they found themselves. The acceptance and use of these innovations may have contributed to human population growth at the very time when extinction of other species was taking place.

The migration and environmental-response models have rather different implications that ean be tested against the archaeological record. The migration model proposes that the Clovis culture suddenly appeared as a consequence of a migration from northeast Asia. This model predicts that the oldest fluted point sites should occur in northern North America and the youngest ones should occur in southern South America. Furthermore, it assumes that Clovis is a single population with one dominant culture. Given these assumptions, homogeneity of tool assemblages is to be expected from site to site (Fig. 3 ).

By contrast, the environmental-response model proposes that people existed in the Americas prior to the advent of Clovis and that local populations responded to new conditions, through innovation and by accepting ideas that originated elsewhere, in the light of their own knowledge and regional circumstances. This model predicts that archaeological remains that pre-date Clovis should be found, in America. It also postulates that human response to changing environmental conditions should first occur in those areas first affected, that is away from the buffered glacial ice margins. Thus the fluted point pattern and other coeval projectile point patterns should be oldest in areas that first experienced rapid environmental change and youngest in areas buffered by the retreating ice. Human populations would have followed large game animals and expanded into new areas vacated by the ice.

\section{An Interplay of Models}

In summary, the question of Clovis origins hangs in the balance of the interplay between the migration and environmental-response models. While it is difficult to directly test these continental-scale models, they can be considered on a regional level. By comparing the details from a series of regional arehaeological records in North and South America, it will be possible to examine the significance of these two competing models on an inter- continental seale. In this 1000 to 800 year-long window there will be ample opportunity to compare findings and plan new research directions.

INQUA '87. Symposium C: Peopling of the New World. Organizers: R. Bonnichsen (U.S.A.) and K.R. Fladmark (Canada).

Dr. R. Bonnichsen is Director of the Center for the Study of Early Man, University of Maine (495 College Avenue, Orono, Maine 04473 , U.S.A.). His research is focussed on the peopling of the Americas with topical emphases on human adaptation to ice marginal environments, taphonomy, and lithic technology. He is currently working on environmental archaeology research projects in northern Maine and southwestern Miontana.

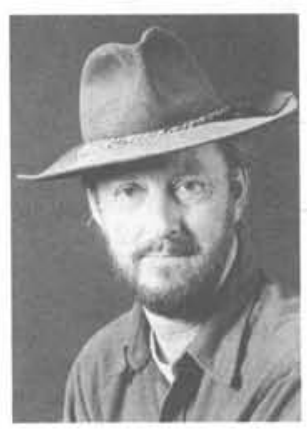

\section{References}

Haynes, C.V., 1966. Elephant hunting in North America. Seientific American v. 214, 6, p. 104-112.

Haynes, C.V., 1969. The earliest Americans. Science v. 166, no. 3906 , p. $709-716$.

Haynes, C.V., 1973. Elephant hunting in North America. In: Early man in America. W.H., Freeman, San Francisco, p. 44-52.

Haynes, C.V., 1980. The Clovis culture. In: Rutter, N.W. and Schweger, C.E. (eds.), Special AMQUA issue: The ice-free corridor and peopling of the New World. Canadian Journal of Anthropology, 1, p. 115-121.

Kutzbach, John E., 1983. Modeling of Holocene climates. In: Wright, H.E., Jr. (ed.), The Holocene: late Quaternary environments of the United States v. 2. University of Minnesota Press, Minneapolis, p. 271-277.

Kutzbach, John E., 1984. The seasonal nature of climatic forcing and responses on Quaternary time scales - with emphasis on the period since the last glacial maximum. In: American Quaternary Association eighth biennial meeting program and abstracts, Boulder, p. 70-71.

Martin, P.S., 1967. Prehistoric Overkill. In: Martin, P.S. and Wright, H.E., Jr. (eds.), Pleistocene extinetions: The search for a cause. Yale University Press, New Haven, p. 75-20.

Martin, P.S., 1973. The discovery of America. Science, v. 179 , p. $969-974$.

Martin, P.S. and Klein, R.G., 1984. Quaternary extinetions: A prehistoric revolution. University of Arizona Press, Tueson, p. 892.

Mosiman, J.E. and Martin, P.S., 1975. Simulating overkill by Paleo-indians. American Scientist, v. 63, p. 304-313.

Ruddiman, W.F. and Wright, H.E., Jr., in press. North America and adjacent oceans during the last deglaciation. The geology of North America, v.K-3. Geological Society of America, Boulder. 